\title{
Inactivation of the ventral tegmental area abolished the general excitatory influence of Pavlovian cues on instrumental performance
}

\author{
Anja Murschall and Wolfgang Hauber ${ }^{1}$ \\ Abteilung Tierphysiologie, Biologisches Institut Universität Stuttgart, D-70550 Stuttgart, Germany
}

\begin{abstract}
Pavlovian stimuli can markedly elevate instrumental responding, an effect known as Pavlovian-instrumental transfer (PIT). As the role of the ventral tegmental area (VTA) in PIT is yet unknown, we examined the effects of transient VTA inactivation by direct microinjections of a mixture of the $G A B A_{A}$ and $G A B A_{B}$ receptor agonists, muscimol and baclofen. Results reveal that PIT, i.e., the increase in instrumental responding during presentation of a Pavlovian stimulus, was abolished by intra-VTA microinjections of muscimol/baclofen. These data provide the first evidence that the VTA mediates Pavlovian influences on instrumental behavior.
\end{abstract}

Appetitive Pavlovian stimuli can markedly elevate instrumental responding, a phenomenon termed Pavlovian-instrumental transfer (Estes 1948; Lovibond 1983; for review, see Dickinson and Balleine 1994). Pavlovian-instrumental transfer (PIT) probably reflects the excitatory effects of Pavlovian stimuli on instrumental responding and can be mediated by both the general motivational and the sensory-specific influences of the Pavlovian CS (for review, see Dickinson and Balleine 2002). Hence, general and outcome-specific forms of PIT can be separated experimentally (e.g., Corbit and Balleine 2005). The amygdala and nucleus accumbens are key structures in mediating PIT (Blundell et al. 2001; Hall et al. 2001; Holland and Gallagher 2003; Corbit and Balleine 2005). However, little is known about the neurochemical basis of PIT. There is consistent evidence for a dopaminergic involvement as systemic administration of dopamine receptor antagonists eliminated (Dickinson et al. 2000), whereas intraaccumbens microinjection of amphetamine enhanced PIT (Wyvell and Berridge 2000). Therefore, PIT may depend upon the regulation of the dopaminergic innervation of the nucleus accumbens by projections from the amygdala to the ventral tegmental area (VTA) (Hall et al. 2001). However, the role of the VTA in PIT is yet unknown. Here, we examined the effects of VTA inactivation on PIT by direct microinjections of a mixture of the $\mathrm{GABA}_{\mathrm{A}}$ and $\mathrm{GABA}_{\mathrm{B}}$ agonists, muscimol, and baclofen.

First, 12 sessions of Pavlovian training were given. Stimulusdirected behavior during Pavlovian training was measured by calculating the approach ratio, i.e., the percentage of time spent in the food receptacle during CS+ and the percentage of time spent in the food receptacle during ISI as follows: Approach ratio $=(\% \mathrm{CS}) /(\% \mathrm{CS}+\% \mathrm{ISI})$. The mean approach ratio from all subjects $(n=32)$ during Pavlovian training significantly increased as displayed in Figure 1A. A one-way ANOVA conducted on the training data revealed a significant effect of training day $\left(F_{(11,341)}=13.1, P<0.0001\right)$.

Then, animals received nine instrumental training sessions. The number of lever presses per minute across days of instrumental training is displayed in Figure 1B. A one-way ANOVA revealed a significant effect of training day $\left(F_{(8,248)}=42.5, P<0.0001\right)$. The transfer test revealed that presentation of the Pavlovian

\footnotetext{
'Corresponding author.

E-mail hauber@bio.uni-stuttgart.de; fax 49-711-685-5090.

Article published online ahead of print. Article and publication date are at http://www.learnmem.org/cgi/doi/10.1101/lm.127106.
}

stimulus (CS+) enhanced lever pressing relative to the nonreinforced stimulus (CSo) and ISI, but this effect differed across treatment groups as shown in Figure 1C. A one-way ANOVA indicated that lever press rates during presentation of CS+ and CSo did not depend on CS identity (tone, white noise; counterbalanced). Therefore, tone and white noise were equally effective as CSs and respective data were collapsed. In rats with intra-VTA saline injections the $\mathrm{CS}+$ markedly elevated responding relative to the CSo and ISI, while in rats with intra-VTA baclofen/ muscimol injections, this transfer effect was impaired. The statistical analysis confirmed this description. A two-way ANOVA with treatment as between-subject factor (four levels: 0/0, 0.03/0.003, $0.06 / 0.006,0.08 / 0.008 \mathrm{nmol}$ baclofen/muscimol) and stimulus as within-subject factor (three levels: ISI, CSo, and CS+) revealed a significant main effect of treatment $\left(F_{(3,28)}=3.220 ; P=0.038\right)$, a significant main effect of stimulus $\left(F_{(2,56)}=21.405 ; P<0.0001\right)$, and a treatment $\times$ stimulus interaction $\left(F_{(6,56)}=4.741 ; P<0.0001\right)$. Simple effects analysis revealed an effect of treatment during CS+ $\left(F_{(3,28)}=5.30 ; P<0.01\right)$, but not during CSo $\left(F_{(3,28)}=0.98\right.$; $P=0.42)$ or ISI $\left(F_{(3,28)}=1.31 ; P=0.29\right)$, indicating that drugs did not affect baseline responding. Simple effects analysis further revealed a significant effect of stimulus type in groups treated with saline $\left(F_{(2,20)}=11.84 ; P<0.001\right), 0.03 / 0.003 \mathrm{nmol}$ baclofen/ muscimol $\left(F_{(2,10)}=7.91 ; P<0.01\right)$, and $0.06 / 0.006 \mathrm{nmol}$ baclofen/ muscimol $\left(F_{(2,10)}=5.42 ; P<0.05\right)$, but not in the group treated with $0.08 / 0.008 \mathrm{nmol}$ baclofen/muscimol $\left(F_{(2,16)}=0.094\right.$; $P=0.91$. Post hoc comparisons using the Tukey HSD test revealed higher responding during CS+ relative to ISI and CSo in the saline (ISI: $P<0.01$, CSo: $P<0.01$ ) and 0.03/0.003 nmol baclofen/muscimol (ISI: $P<0.05$, CSo: $P<0.05$ ) group, thus indicating a transfer effect. In the $0.06 / 0.006 \mathrm{nmol}$ baclofen/muscimol group, the elevation of responding during CS+ versus ISI and CSo (ISI: $P=0.05$, CSo: $P=0.036$ ) was close to the significance criterion indicating a lower transfer effect. The location of the injection cannulae tips within the VTA is shown in Figure 2.

The present study demonstrates that VTA inactivation by a mixture of the $\mathrm{GABA}_{\mathrm{A}}$ and $\mathrm{GABA}_{\mathrm{B}}$ receptor agonists, muscimol, and baclofen, abolished PIT. These data provide the first evidence that conveying Pavlovian influences on instrumental behavior requires neural activity in the VTA.

The effects of baclofen and muscimol on PIT are not attributable to nonspecific drug effects on response capacity. First, during presentation of the nonreinforced stimulus (CSo) and during ISI, lever-press rates in subjects with intra-VTA microinjection of 

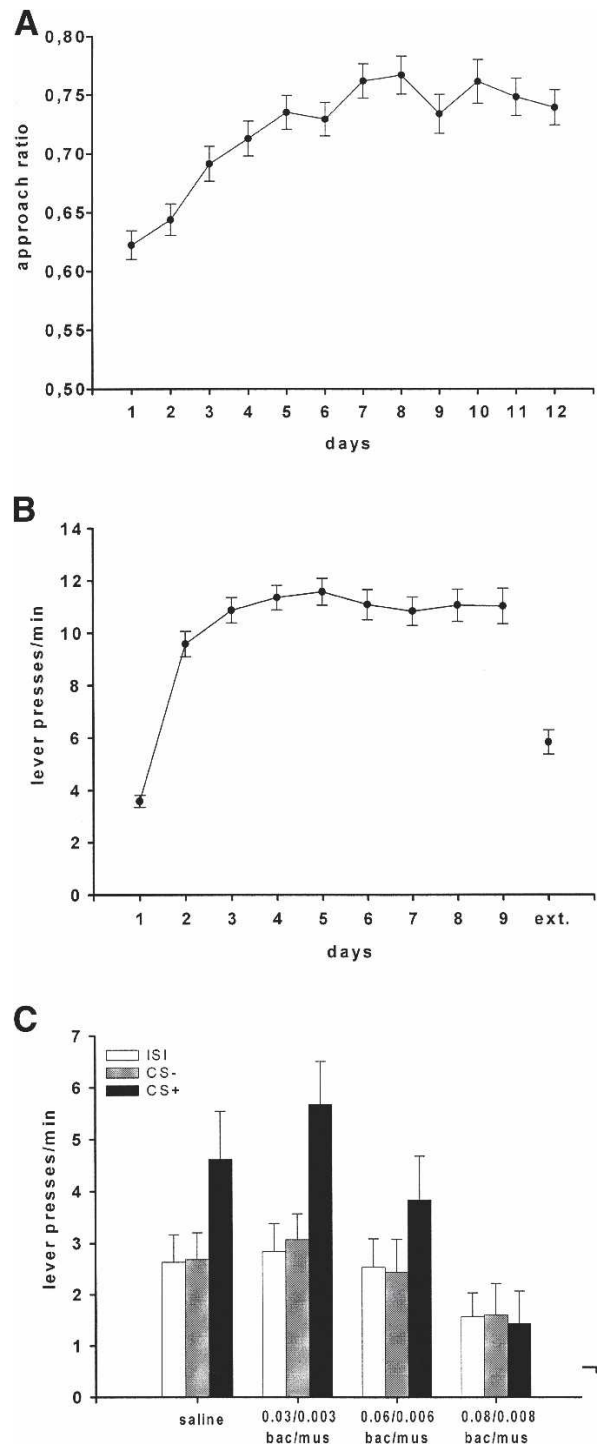

Figure 1. Pavlovian-instrumental transfer. $(A)$ Pavlovian training. Mean approach ratio $( \pm S E M)$, i.e., the ratio of time spent in the food receptacle during CS+ and time spent in the food receptacle during ISI, across $12 \mathrm{~d}$ of training $(n=32)$. (B) Instrumental training. Mean lever presses $( \pm$ SEM) across $9 \mathrm{~d}$ of training and during a subsequent extinction session without reinforcement $(n=32)$. (C) Transfer test. Effect of intra-VTA injection of saline $(n=11), 0.03 / 0.003 \mathrm{nmol}(n=6), 0.06 / 0.006 \mathrm{nmol}$ $(n=6)$, or $0.08 / 0.008 \mathrm{nmol}$ baclofen/muscimol $(n=9)$ on mean lever presses ( \pm SEM) during presentation of CS+ and CSo as well as during ISI. The CS+ significantly elevated responding relative to CSo and ISI after saline (ISI: $P<0.01$, CSo: $P<0.01), 0.03 / 0.003 \mathrm{nmol}$ baclofen/muscimol (ISI: $P<0.05$, CSo: $P<0.05$ ), and $0.06 / 0.006 \mathrm{nmol}$ baclofen $/ \mathrm{muscimol}$ (ISI: $P=0.05$, CSo: $P=0.036$ ), but not after $0.08 / 0.008 \mathrm{nmol}$ baclofen/ muscimol (n.s.; ANOVA followed by a post hoc Tukey HSD test); (ext) extinction session; (CS+) conditioned stimulus; (CSo) unconditioned stimulus; (ISI) interstimulus interval (2 min in duration, respectively).

vehicle and baclofen/muscimol were largely similar; only the high dose $(0.08 / 0.008 \mathrm{nmol}$ baclofen/muscimol) did not significantly reduce lever-press rates. Second, in the PIT test used here, intra-VTA microinjections of doses of 0.1/0.01 nmol baclofen/ muscimol and above are necessary to induce a motor impairment associated with a considerable reduction in lever pressing (A. Murschall, unpubl.). Third, in a number of other instrumental tasks, baclofen/muscimol-induced VTA inactivation using the same doses as here did not impair response capacity (McFarland and Kalivas 2001; Di Ciano and Everitt 2004; McFarland et al. 2004). Moreover, behavioral effects after microinjection of baclofen/muscimol into the VTA compared to the substantia nigra are distinct (McFarland and Kalivas 2001), suggesting that drug diffusion to adjacent brain areas might not account for the present results.

PIT critically depends upon the integrity of the nucleus accumbens and the amygdala. For instance, lesions of the nucleus accumbens and the central nucleus of the amygdala (CeN) reduced PIT, while lesions of the basolateral amygdala (BLA) had no effect (Hall et al. 2001; Holland and Gallagher 2003). In contrast to these findings, Blundell et al. (2001) reported that BLA, but not CeN lesions, abolished PIT. These apparently discrepant results are likely to be brought about by different training protocols and forms of PIT used in these experiments. A recent study by Corbit and Balleine (2005) addressing this issue revealed that both BLA and CeN contribute to PIT, but their involvement depends on the form of PIT, i.e., the BLA conveys the outcomespecific form of PIT, while the CeN serves the general form of PIT. The general form of PIT is thought to rely on the general motivating effects of an appetitive Pavlovian stimulus, i.e., instrumental responding may be enhanced during presentation of an appetitive CS+ as a result of nonspecific motivational arousal. The outcome-specific form of PIT refers to another mechanism through which Pavlovian CSs probably modulate instrumental responding, i.e., an appetitive $\mathrm{CS}+$ may also act to energize a specific instrumental action-in the presence of other response options-with which it shares the same outcome.

The present as well as various other studies (Hall et al. 2001; Holland and Gallagher 2003) used a PIT procedure in which rats were trained on a single lever, and the effect of a single Pavlovian stimulus on performance of that lever was measured. This protocol generates a form of PIT that relies on the general motivational influence of the Pavlovian stimulus and is mediated by the CeN (Corbit and Balleine 2005). Thus, though not explicitly examined, the transfer test used here might involve the general

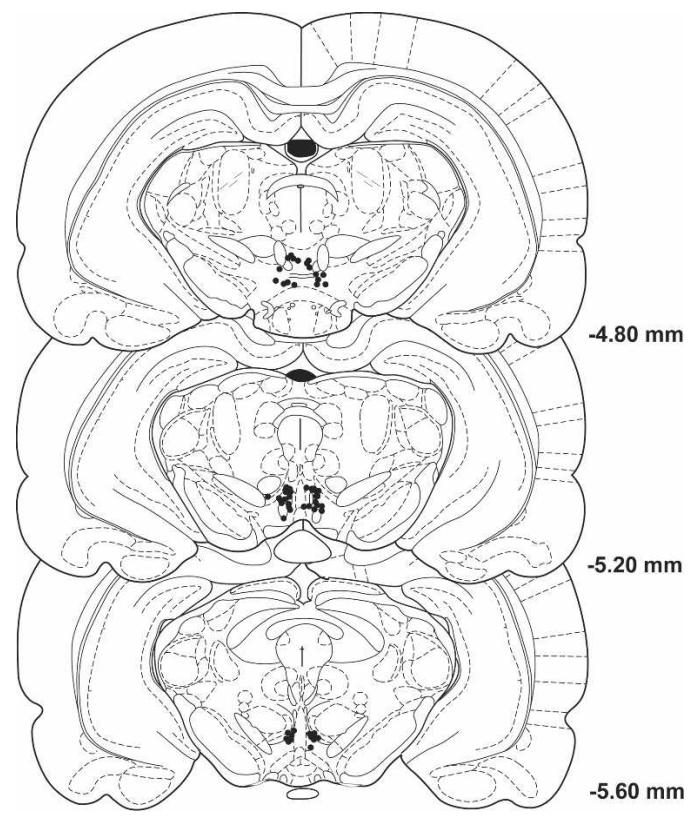

Figure 2. Cannulae placement in the VTA. The schematics depict the location of the injection cannulae tips $(\bullet)$ in the VTA for all rats $(n=32)$. Plates are adaptations from Paxinos and Watson (1986), with permission from Elsevier @ $)$ 1986. Numbers beside each plate correspond to millimetres anterior to bregma.

\section{Learning \& Memory}

www.learnmem.org 
form of PIT mediated by the CeN. As stimulation of mesoaccumbens dopamine neurotransmission increased PIT (Wyvell and Berridge 2000), the CeN has been suggested to control PIT by modulating the activity of mesoaccumbens dopamine projections (Hall et al. 2001) through efferents to the vicinity of midbrain dopamine neurons (Wallace et al. 1992). Notably, CeN projections to the midbrain utilize $\gamma$-amino-butyric acid (GABA) as neurotransmitter (Swanson and Petrovich 1998). Furthermore, the input from the CeN to midbrain dopamine neurons might not be direct, but probably involves projections to nondopamine neurons (Wallace et al. 1992), which partially express GABA receptors (Suaud-Chagny et al. 1992). Accordingly, inactivation of the CeN was associated with decreased basal levels of dopamine efflux in the ACB (Ahn and Phillips 2002). Our findings correspond to this account and demonstrate directly a VTA involvement in mediating the general form of PIT, probably as a key component of a circuit from the $\mathrm{CeN}$ to the nucleus accumbens.

Drug-associated cues play an important role in relapse to drug use in humans and animals (Hyman 2005). For instance, contingent presentation of previously cocaine-related cues can reinstate cocaine-seeking behavior in rats (Everitt and Wolf 2002). PIT-which involves noncontingent stimulus presentation-probably plays a major role in CS-induced reinstatement of drug seeking as well (Ludwig et al. 1974; Tiffany and Drobes 1990; Gawin 1991; O'Brien et al. 1998); however, its contribution to these processes has been rarely investigated. Weiss et al. (2000, 2001) reported that noncontingent presentation of a previously cocaine-paired cue massively elevated cocaine seeking and increased intra-accumbens dopamine release. These effects might reflect an impact of PIT on relapse, and our present results suggest that they could be mediated, at least in part, by the VTA conveying the general motivational impact of cocaine-associated cues on instrumental responding. Furthermore, our findings raise the possibility that a VTA inactivation thereby blocking the general motivating influence of cocaine-related cues on instrumental behavior contributes to the decreased propensity to cueinduced cocaine seeking and reinstatement observed after systemic administration of $\mathrm{GABA}_{\mathrm{B}}$ receptor agonists $\left(\mathrm{O}^{\prime}\right.$ Brien et al. 1998; Di Ciano and Everitt 2003). However, this view requires direct experimental support, e.g., by investigating whether a pharmacological manipulation of VTA $\mathrm{GABA}_{\mathrm{B}}$ receptors interferes with the general motivational influence of cocaineassociated cues on instrumental behavior.

Taken together, our present results suggest that the VTA mediates the general motivational impact of Pavlovian stimuli on instrumental responding, probably as part of a circuit comprising projections from the $\mathrm{CeN}$ to midbrain dopaminergic neurons.

\section{Materials and Methods}

All animal experiments were conducted according to the German Law on Animal Protection and approved by the proper authorities.

Subjects were 32 male Lister hooded rats (HarlanWinkelmann) weighing 240-359 $\mathrm{g}$ at the time of surgery. Rats were housed in groups at $20 \pm 2^{\circ} \mathrm{C}$ on a 12 -h light/12-h dark cycle (lights on at 7:00 a.m.) with ad-libitum access to water and standard laboratory chow (Altromin). Prior to the onset of behavioral training, food was restricted to $15 \mathrm{~g}$ per animal/day.

For stereotaxic surgery, animals were anaesthetized with ketamine HCL (120 mg/kg; Bela-Pharm) and xylazine HCL (4 mg/ kg Rompun; Bayer) and secured in a stereotaxic apparatus (Kopf Instruments). Bilateral guide cannulae $(0.8 \mathrm{~mm}$ outer diameter; TSK) aimed at the VTA were implanted using standard stereotaxic procedures. The coordinates were: 5.2 anterior bregma, \pm 1.2 to \pm 2.0 lateral to midline and 8.0 ventral from the skull (Paxinos and Watson 1986) with the guide cannulae positioned in an angle of about $8^{\circ}$ from the midline. Each rat was given at least 5 $\mathrm{d}$ to recover from surgery before the onset of behavioral training.

Animals received bilateral microinjections of a combination of the $\mathrm{GABA}_{\mathrm{B}}$ receptor agonist (R)-4-Amino-3-(4-chlorophenyl)butanoic acid (baclofen [bac]; Biotrend $\mathrm{GmbH}$ ) and the $\mathrm{GABA}_{\mathrm{A}}$ receptor agonist 5-aminomethyl-3-hydroxyisoxazole (muscimol [mus]; Biotrend $\mathrm{GmbH}$ ). Drugs were dissolved in physiological saline $(0.9 \%)$ and injected at doses of $0.08 / 0.008$ bac/mus (0.08 nmol baclofen and $0.008 \mathrm{nmol}$ muscimol), $0.06 /$ $0.006 \mathrm{bac} / \mathrm{mus}(0.06 \mathrm{nmol}$ baclofen and $0.006 \mathrm{nmol}$ muscimol), and 0.03/0.003 bac/mus (0.03 nmol baclofen and $0.003 \mathrm{nmol}$ muscimol); control subjects received bilateral vehicle injections of $0.3 \mu \mathrm{L}$ of saline.

All injections were delivered through injection cannulae ( $0.45 \mathrm{~mm}$ outer diameter; Braun) in a volume of $0.3 \mu \mathrm{L}$ over a 1-min interval; injection cannulae were left in position for a further minute to allow for diffusion. After injection, each animal remained in its home cage for an additional $10 \mathrm{~min}$ before being placed in the test chamber.

To adapt animals to the microinjection procedure, they received four sham injections including handling, insertion of injection cannulae dummies, and operation of the injection pump (without running an injection) prior to behavioral training on days 7-9 of instrumental training as well as the reminder session. On the day before the transfer test, i.e., the instrumental extinction session, all animals received a single intra-VTA injection of vehicle $(0.3 \mu \mathrm{L}$ saline $)$

The behavioral procedures were performed in identical operant chambers $(24 \times 21 \times 30 \mathrm{~cm})$ (Med Associates) equipped with a food receptacle, a food dispenser, and a retractable lever on the left side of the food receptacle. Illumination was provided by a $24 \mathrm{~V} / 3 \mathrm{~W}$ house light mounted on the top center of the wall opposite the food receptacle. The speaker that delivered the auditory conditioned stimuli was mounted on the wall opposite to the lever and the food receptacle.

The behavioral procedure (see Murschall and Hauber 2005 for details) was based on a protocol by Dickinson et al. (2000). First, all subjects received one session of magazine training; food pellets (45 mg pellets, Bioserve) were delivered on a random time (RT) 30-sec schedule with no lever available. Thereafter, 12 sessions of Pavlovian training were given. Two $80-\mathrm{dB}$ auditory stimuli (3-kHz tone and white noise) served as CS+ and CSo in a counterbalanced fashion. Each session contained six 2-min presentations of the CS+, followed by an interstimulus interval (ISI) of 2-4 min. Reward was delivered only during the presentation of the CS+ on a RT 30-sec schedule. Then, animals received nine instrumental training sessions with the lever inserted. Responding on the lever was reinforced on a random interval (RI) schedule starting with RI 2-sec during the first session. For the next two sessions, the schedule was increased to RI 15-sec and RI 30-sec, and, for the remaining six sessions to RI 60-sec; a session ended after 30 min. Subsequently, one Pavlovian reminder was given. This session was similar to Pavlovian training sessions, except that two additional, nonreinforced 2-min presentations of the alternative neutral stimuli (CSo) and additional ISI were given preceding the fifth and following the sixth presentation of the CS+. In addition, the animals received a single 30-min instrumental extinction session with the lever available, but not reinforced.

The transfer effect was tested in extinction, while the lever was inserted into the operant chamber. Each stimulus (CS+ and CSo) was 2 min in duration and preceded by a 2-min ISI period. The session always started with the presentation of the white noise, thus counterbalancing the order of presentation of CS+ and CSo within each group, and ended after four presentations of each stimulus type (CS+ and CSo). Subjects were assigned to four different groups receiving either $0.08 / 0.008$ baclofen/muscimol $(n=9), 0.06 / 0.006$ baclofen/muscimol $(n=6), 0.03 / 0.003$ baclofen/muscimol $(n=6)$, or saline $(n=11)$ prior to the transfer test.

After completion of the experiment, rats were killed with an overdose of sodium pentobarbital (150 mg/kg) (Sigma-Aldrich) to control for correct cannulae placements. Brains were removed, 
fixed in $10 \%$ formalin for $24 \mathrm{~h}$, and stored in 30\% glucose. Coronal brain sections $(40 \mu \mathrm{m})$ were collected, mounted on coated slides, and stained with cresyl violet. Cannulae placements were verified with reference to the atlas of Paxinos and Watson (1986).

Data from Pavlovian and instrumental training were subjected to an analysis of variances (ANOVA) for repeated measures with training day as factor. Pavlovian-instrumental transfer data were subjected to an ANOVA for repeated measures with treatment as between-subject factor and stimulus as within-subject factor. Significant interactions were further investigated by an analysis of simple effects. The level of statistical significance was $P<0.05$.

\section{Acknowledgments}

This research was supported by the Deutsche DFG (Ha2340/6-1).

\section{References}

Ahn, S. and Phillips, A.G. 2002. Modulation by central and basolateral amygdalar nuclei of dopaminergic correlates of feeding to satiety in the rat nucleus accumbens and medial prefrontal cortex. J. Neurosci. 22: 10958-10965.

Blundell, P., Hall, G., and Killcross, S. 2001. Lesions of the basolateral amygdala disrupt selective aspects of reinforcer representation in rats. J. Neurosci. 21: 9018-9026.

Corbit, L.H. and Balleine, B. 2005. Double dissociation of basolateral and central amygdala lesions on the general outcome-specific forms of Pavlovian-instrumental transfer. J. Neurosci. 25: 962-970.

Di Ciano, P. and Everitt, B.J. 2003. The GABA $_{\mathrm{B}}$ receptor agonist baclofen attenuates cocaine- and heroin-seeking behavior by rats. Neuropsychopharmacology 28: 510-518.

. 2004. Contribution of the ventral tegmental area to cocaine-seeking maintained by a drug-paired conditioned stimulus in rats. Eur. J. Neurosci. 19: 1661-1667.

Dickinson, A. and Balleine, B. 1994. Motivational control of goal-directed action. Anim. Learn. Behav. 22: 1-18.

. 2002. The role of learning in the operation of motivational systems. In: Stevens' handbook of experimental psychology, learning, motivation and emotion, Vol. 3, 3rd ed. (ed. R. Gallistel), pp. 497-533. John Wiley \& Sons, Inc., New York.

Dickinson, A., Smith, J., and Mirenowicz, J. 2000. Dissociation of Pavlovian and instrumental incentive learning under dopamine antagonists. Behav. Neurosci. 114: 468-483.

Estes, W. 1948. Discriminative conditioning. II. Effects of a Pavlovian conditioned stimulus upon a subsequently established operant response. J. Exp. Psychol. 38: 173-177.

Everitt, B.J. and Wolf, M.E. 2002. Psychomotor stimulant addiction: A neural systems perspective. J. Neurosci. 22: 3312-3320.

Gawin, F.H. 1991. Cocaine addiction: Psychology and neurophysiology. Science 251: 1580-1586.

Hall, J., Parkinson, J.A., Connor, T.M., Dickinson, A., and Everitt, B.J. 2001. Involvement of the central nucleus of the amygdala and nucleus accumbens core in mediating Pavlovian influences on instrumental behaviour. Eur. J. Neurosci. 13: 1984-1992.
Holland, P.C. and Gallagher, M. 2003. Double dissociation of the effects of lesions of basolateral and central amygdala on conditioned stimulus-potentiated feeding and Pavlovian-instrumental transfer. Eur. J. Neurosci. 17: 1680-1694.

Hyman, S.E. 2005. Addiction: A disease of learning and memory. Am. J. Psychiatry 162: 1414-1422.

Lovibond, P.F. 1983. Facilitation of instrumental behavior by a Pavlovian appetitive conditioned stimulus. J. Exp. Psychol. Anim. Behav. Process. 9: 225-247.

Ludwig, A.M., Wikler, A., and Stark, L.H. 1974. The first drink: Psychobiological aspects of craving. Arch. Gen. Psychiatry 30: 539-547.

McFarland, K. and Kalivas, P.W. 2001. The circuitry mediating cocaine-induced reinstatement of drug-seeking behavior. J. Neurosci. 21: $8655-8663$.

McFarland, K., Davidge, S.B., Lapish, C.C., and Kalivas, P.W. 2004. Limbic and motor circuitry underlying footshock-induced reinstatement of cocaine-seeking behavior. J. Neurosci. 24: 15511560.

Murschall, A. and Hauber, W. 2005. Effects of a systemic AMPA/KA and NMDA receptor blockade on Pavlovian-instrumental transfer. Psychopharmacology 182: 1-7.

O'Brien, C.P., Childress, A.R., Ehrman, R., and Robbins, S.J. 1998. Conditioning factors in drug abuse: Can they explain compulsion? J. Psychopharmacol. 12: 15-22.

Paxinos, G. and Watson, C. 1986. The rat brain in stereotaxic coordinates. Elsevier Academic Press, San Diego, CA.

Suaud-Chagny, M.F., Chergui, K., Chouvet, G., and Gonon, F. 1992. Relationship between dopamine release in the rat nucleus accumbens and the discharge activity of dopaminergic neurons during local in vivo application of amino acids in the ventral tegmental area. Neuroscience 49: 63-72.

Swanson, L.W. and Petrovich, G.D. 1998. What is the amygdala? Trends Neurosci. 21: 323-331.

Tiffany, S.T. and Drobes, D.J. 1990. Imagery and smoking urges: The manipulation of affective content. Addict. Behav. 15: 531-539.

Wallace, D.M., Magnuson, D.J., and Gray, T.S. 1992. Organization of amygdaloid projections to brainstem dopaminergic, noradrenergic, and adrenergic cell groups in the rat. Brain Res. Bull. 28: 447-454.

Weiss, F., Maldonado-Vlaar, C.S., Parsons, L.H., Kerr, T.M., Smith, D.L., and Ben-Shahar, O. 2000. Control of cocaine-seeking behavior by drug-associated stimuli in rats: Effects on recovery of extinguished operant-responding and extracellular dopamine levels in amygdala and nucleus accumbens. Proc. Natl. Acad. Sci. 97: 4321-4326.

Weiss, F., Martin-Fardon, R., Ciccocioppo, R., Kerr, T.M., Smith, D.L., and Ben-Shahar, O. 2001. Enduring resistance to extinction of cocaine-seeking behavior induced by drug-related cues. Neuropsychopharmacology 25: 361-372.

Wyvell, C.L. and Berridge, K.C. 2000. Intra-accumbens amphetamine increases the conditioned incentive salience of sucrose reward: Enhancement of reward "wanting" without enhanced "liking" or response reinforcement. J. Neurosci. 20: 8122-8130.

Received November 24, 2005; accepted in revised form January 2, 2006.
126 Learning \& Memory

www.learnmem.org 


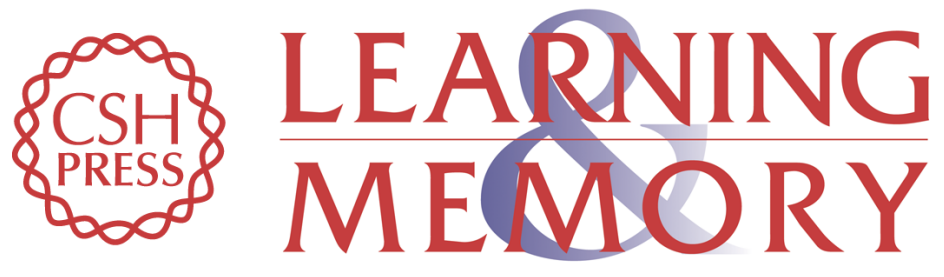

\section{Inactivation of the ventral tegmental area abolished the general excitatory influence of Pavlovian cues on instrumental performance}

Anja Murschall and Wolfgang Hauber

Learn. Mem. 2006, 13:

Access the most recent version at doi:10.1101//m.127106

References This article cites 24 articles, 9 of which can be accessed free at:

http://learnmem.cshlp.org/content/13/2/123.full.html\#ref-list-1

License

Email Alerting Receive free email alerts when new articles cite this article - sign up in the box at the Service top right corner of the article or click here. 